Научная статья

УДК 316.44

DOI: $10.17213 / 2075-2067-2021-5-53-60$

\title{
СПЕЦИФИКА ПРЕДСТАВЛЕННОСТИ ДИАСПОР В СОЦИАЛЬНОЙ СТРУКТУРЕ СОВРЕМЕННЫХ ГОСУДАРСТВ
}

\author{
Евгений Анатольевич Слизский \\ Южжно-Российский государственный политехнический университет (НПИ) \\ имени М. И. Платова, Новочеркасск, Россия \\ slizskiy@bk.ru, ORCID: 0000-0002-5972-8843, AuthorID РИНЦ: 1124012
}

Аннотация. Цель исследования является социологическое исследование представленности феномена диаспоры в сочиальной структуре современных государств.

Методологическую базу исследования представляют классический аналитический метод, а также социоструктурный анализ, разработанный классиками соичологической мысли. Исходной установкой проведения аналитического исследования является потребность в обновлении и накоплении знаний о межэтнических отнотениях в современном трансформирующемся обществе. В частности, исходным пунктом являлся следующий тезис: глобализация привела к тому, что трансформачии подвергаются все сферы общества, в том числе и начиональная и этническая идентичность. К используемым научным методам относится сравнительный, причинно-следственный и статистический анализ.

Результаты исследования. Наџиональный характер и особенности его проявления имеют серьезное значение в формировании стабильной сочиальной среды. Начииональный характер культурно обусловлен и определяет особенности проявления национальной психики в деятельности конкретного субъекта. Государственное регулирование условий пребывания диаспорных групп на территории страны - сложный и противоречивый прочесс. Характер протекания межнациональных отношений зависит от качественных и количественных показателей этнической группы, ее сплоченности, коммуникативной активности и конкретных практикам реализачии идентификационных стратегий. В этой связи государственное регулирование межначиональных отношений нуждается в подробном научном исследовании.

Ключевые слова: диаспоры, национальная идентичность, глобализация, государство, социальная структура

Для цитирования: Слизский Е. А. Специфика представленности диаспор в социальной структуре современных государств // Вестник Южно-Российского государственного технического университета. Серия: Сочиально-экономические науки. 2021. T. 14, №5. С. 53-60. http://dx.doi.org/10.17213/2075-2067-2021-5-53-60.

(C) Слизский Е.А., 2021 
Original article

\title{
THE SPECIFICITY OF THE REPRESENTATION OF DIASPORAS IN THE SOCIAL STRUCTURE OF MODERN STATES
}

\author{
Evgeniy A. Slizskiy \\ Platov South Russian State Polytechnic University (NPI), Novocherkassk, Russia \\ slizskiy@bk.ru, ORCID: 0000-0002-5972-8843, AuthorID RSCI: 1124012
}

\begin{abstract}
The purpose of the study is a sociological study of the representation of the phenomenon of diaspora in the social structure of modern states.

The methodological basis of the research is represented by the classical analytical method, as well as the sociostructural analysis developed by the classics of sociological thought. The initial setting of the analytical research is the need to update and accumulate knowledge about interethnic relations in a modern transforming society. In particular, the starting point was the following thesis: globalization has led to the transformation of all spheres of society, including national and ethnic identity. The scientific methods used include comparative, causal and statistical analysis.
\end{abstract}

The results of the study. The national character and the peculiarities of its manifestation are of serious importance in the formation of a stable social environment. The national character is culturally conditioned and determines the peculiarities of the manifestation of the national psyche in the activity of a particular subject. State regulation of the conditions of stay of diaspora groups in the country is a complex and contradictory process. The nature of the course of interethnic relations depends on the qualitative and quantitative indicators of an ethnic group, its cohesion, communicative activity and specific practices of implementing identification strategies. In this regard, the state regulation of interethnic relations needs a detailed scientific study.

Keywords: diasporas, national identity, globalization, state, social structure

For citation: Slizskiy E. A. The specificity of the representation of diasporas in the social structure of modern states // Bulletin of the South Russian State Technical University. Series: Socio-economic Sciences. 2021; 14(5): 53-60. (In Russ.). http://dx.doi.org/10.17213/2075-2067-2021-5-53-60.

Введение. Межнациональные отношения являются важным аспектом государственной политики в полиэтничном обществе. В зависимости от степени обособленности, локально-исторического и территориального положения существует несколько моделей этнической представленности. Среди прочих классическая диаспора представляет собой сложно структурированную систему социального взаимодействия. Диаспора представлена внутри государства, имея непосредственные каналы связи и коммуникации с государством исхода. При этом не каждая диаспора является сплоченной и не для всех членов диаспоры признак сплоченности является универсальным.
С точки зрения социологии межнациональных отношений, исследование характера и особенностей включенности диаспорных групп в социальную структуру государства видится перспективным. При этом задача государства - реагировать не только на взаимоотношения диаспор с принимающим обществом. Для диаспорно-земляческих сообществ мигранты - это либо «свои», земляки, прибывшие на новое место проживания или заработка, или чужие. Восприятие «своих» может выражаться в принципах похожести и родства, например, общая религия или обычаи. «Чужих» воспринимают, исходя из конкурентности, непохожести обычаев, религии, языка. 
Методология. Методической основой исследования является классический аналитический метод, а также социоструктурный анализ, разработанный такими исследователями, как Р. К. Мертон и Т. Парсонс. При этом в разработке включенности диаспор в социальную среду мы учитывали социокоммуникативный аспект.

Результаты. В современном мире взаимодействие с институтами гражданского общества становится необходимым условием социальной стабильности. В то же время сами условия функционирования социальных институтов значительно трансформируются не только с точки зрения технологий, но и по степени информационной доступности. Гражданское общество должно обладать высокой степенью публичности и хорошим освещением своего функционирования. Это формирует социальное доверие и позволяет более продуктивно взаимодействовать с органами власти различных уровней. В то же время в процессе увеличения степени модернизации общества и коммуникативной сферы в частности на первый план выходит регулирование различных социальных взаимодействий, в том числе и социальных конфликтов.

Социальную стабильность отечественные ученые определяют следующим образом: «процесс создания современных институтов и отношений, ценностей и норм, необходимых для изменения социального типа базисной личности» [7, с. 76]. Эти процессы находятся в прямой зависимости от политических процессов, которые происходят в современном обществе. В то же время общество не имеет точного представления о том, что такое демократия, зачастую оперируя лишь общеизвестными штампами, например: «наличие определенных свобод, а также возможности выбора и выражения мнения. Однако демократические отношения между обществом и властью представляют собой согласие между демократическими принципами и их выполнением обеими сторонами» [7, с. 75].

Политическая элита заинтересована в поддержке большинства, а также наиболее влиятельных групп, в том числе и национальных меньшинств (которые не только прямым, но и косвенным способом влияют на сохранение стабильности в обществе). Именно под- держка большинства «делает режим легитимным, даже при свертывании демократических институтов, которые еще не успели доказать гражданам свою полезность и которые общество еще не готово отстаивать» [10, с. 170].

По мнению исследователя М. Фридмена, развитые институты гражданского общества выступают необходимым условием для существования всех сфер общества, и в первую очередь экономики [8]. Отсутствие порядка в этой сфере приводит к отсутствию социального доверия, что в свою очередь усугубляет хаос во всей государственной системе и приводит к дисфункциональности всех социальных институтов.

Специалисты отмечают, что «национальный характер представлен на двух уровнях: 1) на уровне общественной психологии в форме нерефлексивных смутных обыденных массовых стереотипов и представлений народа о своем собственном национальном характере; 2) на уровне общественной идеологии - в форме рефлексивных теоретических или идеологических концепций национального характера» [2, с. 126]. Однако именно им и определяется включенность определенной нации в социальную структуру государства. Социальные реакции и поведение отдельных представителей отдельных народов дифференцируются посредством проявления национальной психологии.

В современной России национальный и этнический состав очень разнообразен, что приводит к актуализации этнического фактора как необходимого условия стабильного существования общества. В рамках изучаемого нами вопроса интерес представляет такой социальный феномен, как диаспора.

Ряд исследователей определяет термин «диаспора» как этническое сообщество, в силу различных обстоятельств оторванное от своего народа. Классическим определением диаспоры можно считать следующее:

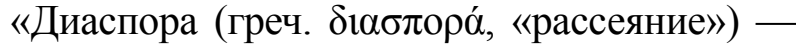
часть народа (этноса), проживающая вне страны своего происхождения, образующая сплоченные и устойчивые этнические группы в стране проживания и имеющая социальные институты для поддержания и развития своей идентичности и общности» [6, с. 112].

Однако подобная трактовка рядом исследователей не признается корректной. 
Высказываются аргументы против слишком расширенного понимания этого термина, «включающего все случаи крупных человеческих перемещений на транснациональном и даже на внутригосударственном уровнях во всей исторически обозримой перспективе» $[3$, с. 90].

Однако на сегодняшний день именно расширенное понимание категории «диаспора» представляется более предпочтительным для большинства социологов. Связано это в первую очередь с таким понятием, как «историческая родина». Большинство ученых сходятся во мнении, что диаспорой корректно называть такую часть народа, которая живет вне родины. Родина же в этом случае представляет собой ту территорию, на которой был сформирован национальный характер той или иной диаспоры.

Глобализация в современном мире привела к возрастанию важности влияния такого фактора, как миграционные процессы, которые ускоряют процесс формирования полиэтничности регионов. Для отечественной истории понимание диаспор актуализировалось уже в 1990-е гг. с распадом СССР, когда миграционные процессы стали проходить более интенсивно. За рубежом первые исследования диаспор появились уже в 1970-е гг. Однако в этих работах рассматривалась так называемая классическая модель диаспоры - еврейская, армянская, греческая - и т.п. исторически более интенсивно участвовавшие в миграционных процессах народы. В качестве основных причин возникновения таких диаспор рассматривались следующие исторические факты: геноцид, угнетение, гонения, угон в рабство и т.П. формы насильственного переселения народов вдали от исторической родины. В классических зарубежных исследованиях выделяют такие критерии диаспоры, как «рассеивание из первоначального исторического центра в различные регионы; коллективная память о стране исхода, ее мифологизация; ощущение, восприятие себя в качестве чужаков в принимающем обществе; стремление к возвращению на родину; помощь, сохранение связей со страной исхода; высокий уровень групповой сплоченности, основанный на высокой степени идентификации со страной исхода» [1, с. 131].
Подобный подход был актуален лишь до 1980-х гг., когда механизм возникновения диаспор трансформировался. В эти годы возросли потоки мигрантов, перемещающихся в большей степени по экономическим причинам: капиталистическая экономика формировала запрос на дешевую рабочую силу, который покрывался за счет мигрантов. В это время возникла необходимость применения так называемого историко-типологического метода.

В результате появилось несколько систем разделения диаспор по различным критериям. Дж. Армстронг разделял диаспоры на классические и «пролетарские» (возникающими в результате миграционных процессов по экономическим причинам). Другой исследователь М. Бруно для классификации диаспор использовал четыре критерия: культура, политика, религия, раса [12]. У Р. Коэна выделяются исторические типы диаспор: жертвы, рабочие, торговые, культурные, империалистические [11] Г. Шеффер разработал более структурированную типологию диаспор: наличие или отсутствие исторической родины, опыта, сформированности и протяженности географически [9].

В 1990-е гг. политическая структура мирового общества изменилась, а с ней изменились и реалии функционирования диаспор. Р. Брубейкер [4] ввел понимание так называемых «диаспор катаклизма». Такие сообщества появлялись в результате изменения границ государств. При этом новые границы разделяли на две разные страны одну этническую группу. Другой исследователь Г. Шеффер ввел в ход термин «транснациональные сети» [9].

На границе XX и XXI веков глобализация ускорила свой темп. Диаспоры также приобрели особенности в своем функционировании в обществе. «Диаспоры, интегрируясь в новые социальные, культурные условия, связываются с ней протяженными и сложными сетями. Данные сети, пересекая границы государств, служат каналом коммуникации для удовлетворения социальных, культурных, образовательных, экономических, политических потребностей диаспор» [1, с. 132].

Диаспора претерпела значительные трансформации в современном обществе. Транснациональные пространства диктуют свои условия существования этнических со- 
обществ. В качестве функций диаспор можно отметить «сохранение устойчивости культурной, социальной, этнической идентичности, интеграция вновь прибывших, поддержание связей со страной исхода и родственными диаспорами» $[1$, с. 133$]$.

Глобализация привела к трансформации коммуникационных связей, что в свою очередь позволило диаспорам наладить активное присутствие в информационном пространстве. Их представители достаточно активно презентуют себя в сети Интернет, используя ее в том числе и для связи с представителями своего этноса, оставшимися на исторической родине. Это привело к появлению терминов «цифровые диаспоры» или «кибердиаспоры» [5].

Интернет не только служит средством коммуникации, отражая реальные образы этносов, но также и создает новый образ, так называемую «цифровую этничность». Исследования такого проявления диаспоральности проводят в рамках так называемой интернетэтнографии. Само интернет-поле открыто для наблюдения и анализа и легко доступно для социологических и антропологических интерпретаций. Исследователи отмечают, что жизнь в диаспоре сильно трансформируется под воздействием цифровых технологий. Члены диаспор получают возможность связываться и общаться друг с другом. Таким образом, сохраняются уже наработанные культурные контакты и этнические модели. Но складываются и новые информационные модели передачи этнической самобытности.

Еще одна модель проявления диаспорной общности - это этнические рынки. Этот феномен получил свое развитие после распада социалистической экономики. Они представляют собой не только модель торговых отношений, но и социокультурных связей. Этнические рынки представляют собой колоритное культурное явление, привлекающее своей самобытностью не только туристов, но и местных жителей. Зачастую их ассортимент - узко-специализированный и представлен лишь в этом месте. Среди местных жителей распространяется мнение, что именно здесь, в этом месте, у представителей этой нации продукт «самый настоящий», поэтому этнические рынки чаще всего экономически прибыльны. Однако такие места представ- ляют собой не только успешное бизнес-пространство, но и социокультурную среду адаптации мигрантов посредством включения их в диаспоральную среду.

Довольно часто этнические рынки разрастаются целыми кварталами, которые называются по имени народа, составляющего управляющую этим рынком диаспору. В качестве примера можно привести так называемые чайна-тауны или целый квартал Брайтон-Бич, прозванный «Маленькой Одессой».

В различных регионах России также довольно широко представлены кавказские, корейские, китайские и т.п. этнические рынки. Однако, несмотря на схожесть в своем истоке, очень часто между представителями этих рынков возникают конфликты, которые порождаются не только различиями в национальной ментальности представителей той или иной диаспоры, но и экономическими различиями, связанными с успешностью функционирования конкретного этнического рынка, пересечениями интересов в той или иной географической местности.

Сам феномен этнических рынков как успешного элемента рыночной экономики можно объяснить, прежде всего, высокой степенью приспособляемости членов диаспор. Установление полезных контактов и связей, новых знакомств, умение располагать к себе людей - все эти качества способствовали выживанию в чужой культурной среде, поэтому среди мигрантов очень быстро складывалась традиция предпринимательской деятельности. К тому же, используя фактор культурной новизны и приспосабливаемость к социуму, диаспоры превращали механизм выживания в средство зарабатывания материальных ресурсов.

Однако само определение диаспор через какие-либо национальные стереотипы зачастую приводило к отторжению обществом каждого члена этой диаспоры как чужака. Таким образом, формировался замкнутый круг: коренное общество воспринимало каждого члена диаспоры в отдельности по определенному социальному шаблону (зачастую негативно окрашенному, так как более предприимчивые и успешные люди вызывали у менее успешных масс зависть), сами же члены диаспор еще глубже уходили от всего сообщества в диаспоральные связи. 
Диаспора создавала защиту всем своим членам, закрывая от деструктивного восприятия коренного населения.

В то же время и для титульной нации обнаружение вокруг себя непривычной культуры и обычаев вызывало значительный дискомфорт. Чаще всего, обладая численным преимуществом на определенной географической территории, члены определенной нации достаточно разобщены на практике. У них нет никаких резонов устанавливать конструктивное общение, даже наоборот, возникает конкуренция за ресурсную и материальную базы.

В то же время, оказавшись оторванными от исторической родины по тем или иным причинам, представители национального меньшинства чувствуют необходимость к самоорганизации и объединению в диаспоральные сообщества с целью защиты интересов каждого члена сообщества.

В результате проведения авторского исследования межнациональных отношений в Краснодарском крае и Республике Адыгея мы пришли к выводу, что ситуация реализации идентификационных стратегий различных этнических групп на территории Краснодарского края и Республики Адыгея непростая, но относительно стабильная. Наиболее интенсивную деятельность по адаптации членов национальной группы к условиям проживания в Краснодарском крае производят татарская и лезгинская группы. Деятельность адыгов по адаптации реализуется естественным образом, что во многом связано с исторической и социокультурной характеристиками проживания данной группы. Что касается узбекской национальной группы, влияние диаспор или землячеств на адаптацию вновь прибывших представителей этнической группы незначительно.

Существуют серьезные затруднения в оценке рассмотренных диаспор и землячеств в социально-экономические и культурные процессы Краснодарского края, что речь в данном случае идет не столько о деятельности диаспор и землячеств как самостоятельных социальных структур, сколько о включенности в социальную жизнь региона отдельных их представителей. Как показали результаты опроса, наибольшую степень включенности в социальную жизнь регио- на проявляют адыги, наименьшую - узбеки. В целом можно судить о том, что сами по себе диаспоры и землячества по большей части проявляют нейтральность, иными словами - векторы их социальной активности направлены на осуществление внутренней деятельности.

Наибольшие сложности в осуществлении идентификационных процессов проявляются в среде узбекской этнической группы. Напротив, наибольшую эффективность осуществления идентификационных процессов демонстрируют представители татарской и адыгской этнических групп. Это обусловлено существенной их включенностью в социальные процессы принимающего общества.

К числу преобладающих механизмов формирования национальной идентичности относятся высокий уровень сопричастности достижениям представителей этнической группы, проведение разнообразных культурных мероприятий, передача национальных ценностей в рамках деятельности института семьи. Тем более значимым становится тот факт, что для представителей современных этнических групп рассматривается в качестве приемлемого формирование семей среди представителей различных национальных групп.

Выявленные в ходе исследования противоречия свидетельствуют о наличии проблемных полей взаимодействия между представителями диаспор и земляческих групп и коренным населением, а также между представителями различных этносов. Вызывает опасение проблема стереотипизации негативных моделей реализации национальной идентичности и переход от локальных частных конфликтов на уровень конфликтов межнациональных.

Существует и еще один значимый фактор. Процессы глобализации приводят к масштабным миграционным потокам. Возникают ситуации, когда, не покидая родной страны, человек оказывается погруженным в культурное многообразие, которое в то же время характеризуется диаспоральными границами. Диаспоры не только не исчезают в современном мире, но и приобретают существенное значение, выступая в качестве инструмента защиты интересов той или иной нации. 
Обсуждение. В качестве дискуссионного момента хотелось бы отметить следующую закономерность. Попытки регулирования миграционных процессов со стороны государства, как правило, представлены в двух видах. Активное прямое воздействие, которое зачастую становится причиной обострения социальной конфликтности, и опосредованное регулирование, предполагающее закрепление определенных обстоятельств и внешних факторов, обуславливающих одни варианты миграции и проблематизирующие другие. Примером первой формы государственного регулирования миграционных процессов является скандально известная ситуация в США на границе с Мексикой. Примером скрытой политики воздействия могут выступать различные реформы, связанные с усложнением или упрощением легализации пребывания на территории принимающего государства. На наш взгляд, аспект конфликтности здесь детерминирован тремя основными факторами. Во-первых, речь идет о сплоченности и степени локализации диаспорной группы. Чем выше уровень непосредственной коммуникации, тем выше динамика реакций на усложнение или упрощение обстоятельств пребывания в принимающем регионе. Во-вторых, очень много зависит от готовности социальной среды к принятию новых членов общества из других регионов. При этом немаловажным аспектом является имидж, точнее, набор стереотипов, представляющий собой собирательный образ выходца из того или иного региона. И, наконец, третьим фактором является количество членов определенной диаспоры, придерживающихся более-менее схожих принципов в плане реализации идентификационных стратегий. Мы полагаем, что данная тематика нуждается в более подробном рассмотрении.

Заключение. Подводя итог, стоит отметить, что регулирование миграционных процессов, а также обстоятельств пребывания диаспорных групп на территории страны является важным аспектом внутригосударственной и международной политики. Несмотря на то, что диаспоры, как правило, представлены общественными организациями, решающими ряд бытовых и социокультурных вопросов, они же в ряде ситуаций представляют собой участника политического взаимодействия. Активная практика государственного регулирования как диаспорных, так и земляческих групп должна проводиться с учетом принципа соблюдения прав и свобод, ориентироваться на предвидение общественного и социокоммуникативного резонанса, а также принимать во внимание особенности исторической и культурной ситуации.

\section{Список источников}

1. Авдашкин А.А. Феномен диаспоры: методологические основы научного исследования // Вестник ЧелГУ. 2015. №2 (357).

2. Анисимова Н.Н. Национальный характер в структуре идентичности // Гуманитарий Юга России. 2019. №3.

3. Бичоева А.Р. Национальная диаспора // Система ценностей современного общества. 2013. №28.

4. Брубейкер Р. «Диаспоры катаклизма» в Центральной и Восточной Европе и их отношения с родинами // Диаспоры. 2000. №3. C. 6-32.

5. Головнев А.В., Белоруссова С. Ю., Киссер Т.С. Веб-этнография и киберэтничность // Уральский исторический вестник. 2018. №1. C. 100-108.

6. Социология: энциклопедия / Сост. А.А. Грицанов, В. Л. Абушенко, Г. М. Евелькин, Г.Н. Соколова, О.В. Терещенко. Мн.: Книжный Дом, 2003.

7. Узлов Ю.А. Социальная стабильность и национальная идентичность гражданского общества // Sciences of Europe. 2017. №12-2(12).

8. Фридмен М. Капитализм и свобода. M., 1982.

9. Шеффер Г. Диаспоры в мировой политике. Диаспоры. М., 2003.

10. Ясин Е. Г. Приживется ли демократия в России? М., 2006.

11. Berthomiere W. Diaspora: An Overview. P. 27.

12. Bruneau M. Diasporas, transnational spaces. P. 39-40.

\section{References}

1. Avdashkin A.A. Fenomen diaspory: metodologicheskie osnovy nauchnogo issledovanija [The phenomenon of the diaspora: 
methodological foundations of scientific research]. Vestnik ChelGU [Bulletin of ChelGU]. 2015; 2 (357). (In Russ.).

2. Anisimova N.N. Nacional'nyj harakter v strukture identichnosti [National character in the structure of identity]. Gumanitarij Juga Rossii [Humanitarian of the South of Russia]. 2019; 3. (In Russ.).

3. Bichoeva A.R. Nacional'naja diaspora [National diaspora]. Sistema cennostej sovremennogo obshhestva [The system of values of modern society]. 2013; 28. (In Russ.).

4. Brubejker R. «Diaspory kataklizma» v Central'noj i Vostochnoj Evrope i ih otnoshenija $\mathrm{s}$ rodinami [«Diasporas of the cataclysm» in Central and Eastern Europe and their relationship with their homelands]. Diaspory [Diasporas]. 2000; 3: 6-32. (In Russ.).

5. Golovnev A. V., Belorussova S. Ju., Kisser T.S. Veb-jetnografija i kiberjetnichnost' [Web ethnography and cyber-ethnicity]. Ural'skij istoricheskij vestnik [Ural Historical Bulletin]. 2018; 1: 100-108. (In Russ.).

6. Sociologija: jenciklopedija [Sociology: encyclopedia]. Sost. A.A. Gricanov, V.L. Abu- shenko, G.M. Evel'kin, G.N. Sokolova, O.V. Tereshhenko [Comp. A.A. Gritsanov, V.L. Abushenko, G. M. Evelkin, G.N. Sokolova, O.V. Tereshchenko]. Minsk: Knizhnyj Dom, 2003. (In Russ.).

7. Uzlov Ju. A. Social'naja stabil'nost' i nacional'naja identichnost' grazhdanskogo obshhestva [Social stability and national identity of civil society]. Sciences of Europe. 2017;12-2 (12). (In Russ.).

8. Fridmen M. Kapitalizm i svoboda [Capitalism and freedom]. Moscow, 1982. (In Russ.).

9. Sheffer G. Diaspory v mirovoj politike. Diaspory [Diasporas in world politics. Diasporas]. Moscow, 2003. (In Russ.).

10. Jasin E. G. Prizhivetsja li demokratija v Rossii? [Will democracy take root in Russia?]. Moscow, 2006. (In Russ.).

11. Berthomiere W. Diaspora: An Overview. P. 27.

12. Bruneau M. Diasporas, transnational spaces. P. 39-40.

Статья поступила в редакцию 27.08.2021; одобрена после рецензирования 26.09.2021; принята к публикащии 28.09.2021.

The article was submitted on 27.08.2021; approved after reviewing on 26.09.2021; accepted for publication on 28.09.2021.

\section{ИНФОРМАЦИЯ ОБ АВТОРАХ}

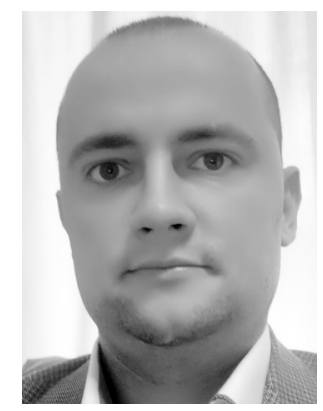

Слизский Евгений Анатольевич - аспирант, Южно-Российский государственный политехнический университет (НПИ) имени М.И. Платова.

Россия, г. Новочеркасск, ул. Просвещения, 132

Evgeny A. Slizsky — Postgraduate Student, Platov South Russian State Polytechnic University (NPI).

132 Prosveshcheniya st., Novocherkassk, Russia 